\title{
Drug resistant tuberculosis in Africa: Current status, gaps and opportunities
}

\begin{tabular}{|c|c|}
\hline $\begin{array}{l}\text { Authors: } \\
\text { Nazir Ismail } \\
\text { Farzana Ismail } \\
\text { Shaheed V. Or } \\
\text { Linsay Blows }{ }^{1} \\
\text { Yasmin Garde } \\
\text { Hendrik Koorr } \\
\text { Philip C. Onye }\end{array}$ & $\begin{array}{l}1,2 \\
\operatorname{lor}^{1} \text { (1) } \\
\text { hof }^{1} \\
\text { oujoh }^{4} \text { (I) }\end{array}$ \\
\hline $\begin{array}{l}\text { Affiliations: } \\
{ }^{1} \text { Center for Tu } \\
\text { National Instit } \\
\text { Communicabl } \\
\text { National Healt } \\
\text { Services, Joha } \\
\text { South Africa }\end{array}$ & $\begin{array}{l}\text { ute for } \\
\text { Diseases, } \\
\text { h Laboratory } \\
\text { nnesburg, }\end{array}$ \\
\hline \multicolumn{2}{|c|}{$\begin{array}{l}{ }^{2} \text { Department of Medical } \\
\text { Microbiology, University } \\
\text { of Pretoria, Pretoria, } \\
\text { South Africa }\end{array}$} \\
\hline \multicolumn{2}{|c|}{$\begin{array}{l}{ }^{3} \text { Department of Internal } \\
\text { Medicine, University of } \\
\text { Witwatersrand, Johannesburg, } \\
\text { South Africa }\end{array}$} \\
\hline \multicolumn{2}{|c|}{$\begin{array}{l}{ }^{4} \text { Africa Centres for Disease } \\
\text { Control and Prevention, } \\
\text { Addis Ababa, Ethiopia }\end{array}$} \\
\hline \multicolumn{2}{|c|}{$\begin{array}{l}\text { Corresponding author: } \\
\text { Nazir Ismail, } \\
\text { naziri@nicd.ac.za }\end{array}$} \\
\hline $\begin{array}{l}\text { Dates: } \\
\text { Received: } 01 \mathrm{~F} \\
\text { Accepted: } 12 \\
\text { Published: } 06\end{array}$ & $\begin{array}{l}\text { eb. } 2018 \\
\text { sept. } 2018 \\
\text { Dec. } 2018\end{array}$ \\
\hline \multicolumn{2}{|c|}{$\begin{array}{l}\text { How to cite this article: } \\
\text { Ismail N, Ismail F, Omar SV, } \\
\text { et al. Drug resistant } \\
\text { tuberculosis in Africa: } \\
\text { Current status, gaps and } \\
\text { opportunities. Afr J Lab Med. } \\
\text { 2018;7(2), a781. https://doi. } \\
\text { org/10.4102/ajlm.v7i2.781 }\end{array}$} \\
\hline \multicolumn{2}{|c|}{$\begin{array}{l}\text { Copyright: } \\
\text { (c) 2018. The Author } \\
\text { Licensee: AOSIS. Thi } \\
\text { is licensed under the } \\
\text { Creative Commons } \\
\text { Attribution License. }\end{array}$} \\
\hline \multicolumn{2}{|l|}{ Read online: } \\
\hline 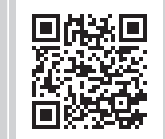 & $\begin{array}{l}\text { Scan this QR } \\
\text { code with your } \\
\text { smart phone or } \\
\text { mobile device } \\
\text { to read online. }\end{array}$ \\
\hline
\end{tabular}

Background: The World Health Organization End TB Strategy targets for 2035 are ambitious and drug resistant tuberculosis is an important barrier, particularly in Africa, home to over a billion people.

Objective: We sought to review the current status of drug resistant tuberculosis in Africa and highlight key areas requiring improvement.

Methods: Available data from 2016 World Health Organization global tuberculosis database were extracted and analysed using descriptive statistics.

Results: The true burden of drug resistant tuberculosis on the continent is poorly described with only $51 \%$ of countries having a formal survey completed. In the absence of this data, modelled estimates were used and reported 92629 drug resistant tuberculosis cases with $42 \%$ of these occurring in just two countries: Nigeria and South Africa. Of the cases estimated, the majority of patients (70\%) were not notified, representing 'missed cases'. Mortality among patients with multi-drug resistant tuberculosis was $21 \%$, and was $43 \%$ among those with extensively drug resistant tuberculosis. Policies on the adoption of new diagnostic tools was poor and implementation was lacking. A rifampicin result was available for less than $10 \%$ of tuberculosis cases in 23 of 47 countries. Second-line drug resistance testing was available in only $60 \%$ of countries. The introduction of the short multi-drug resistant tuberculosis regimen was a welcome development, with $40 \%$ of countries having implemented it in 2016 . Bedaquiline has also been introduced in several countries.

Conclusion: Drug resistant tuberculosis is largely missed in Africa and this threatens prospects to achieve the 2035 targets. Urgent efforts are required to confirm the true burden of drug resistant tuberculosis in Africa. Adoption of new tools and drugs is essential if the 2035 targets are to be met.

\section{Introduction}

Global declines in tuberculosis incidence ${ }^{1}$ provide evidence that political commitment together with aggressive plans to curb the disease can make a difference. These efforts not only stopped the upward spiral of tuberculosis incidence but reversed the trend. The World Health Organization (WHO) has now set targets to end tuberculosis by 2035 and is directing efforts at accelerating the rate of decline, with the expectation of reducing the incidence rate by $90 \%$ and mortality by $95 \%$ compared to levels in $2015 .^{2}$

Africa is home to over 1 billion people and is disproportionately affected by tuberculosis with 2.6 million of the 10.4 million global tuberculosis cases, ${ }^{3}$ making the continent a key geographical area for health interventions. Sub-Saharan Africa, in particular, saw rates rapidly escalate in the early 1990s due to a delayed response to the emergent HIV epidemic at the time. ${ }^{4,5}$ These failures resulted in incidence rates that are the highest in the world and have made the task to end tuberculosis even more challenging. Nonetheless, the tide has changed with the rapid expansion of anti-retroviral therapy resulting in sharp declines in HIV-associated tuberculosis incidence in countries in sub-Saharan Africa, thus offering a window of hope. . $^{6,7}, 8$

Several factors threaten the potential to realise these targets, and key among these is drug resistant tuberculosis. ${ }^{9}$ Unfortunately, much like the global situation, drug resistant tuberculosis in Africa is largely missed with 93000 cases estimated in 2016, while only 27828 (30\%) were diagnosed. ${ }^{3}$ Even when the diagnosis is made, only $59 \%$ achieve a successful treatment outcome.

We present a review of the current status of drug resistant tuberculosis in Africa using data from 2016 WHO global tuberculosis database, ${ }^{10}$ focusing on epidemiology, diagnostic tools and 
therapeutic options. We also highlight and discuss potential priority areas that require strengthening leading up to attaining the 2035 targets.

\section{Situation analysis of drug resistant tuberculosis in Africa}

The best estimate of the burden of drug resistant tuberculosis in Africa requires population-based survey findings, as testing for all tuberculosis cases for rifampicin drug resistance is not done routinely in most countries. Only three countries Mauritius, South Africa and Swaziland - had over $80 \%$ of cases tested for rifampicin (Table 1). Drug resistance surveys are thus the main source of data and are applied based on robust methodologies. ${ }^{11}$ Such surveys have however been completed for only 24 of 47 (51\%) countries (Table 2). When restricted to the last five years, the figure is even lower at $23 \%$ $(11 / 47)$. For 21 countries, no data are available, making planning a response much more challenging and potentially less effective. No country in Africa had a repeat survey in the five-year window recommended, and assessing trends was thus largely not possible based on survey data alone.

In light of the above limitations, WHO applies modelling using available data sources, including surveys. ${ }^{12}$ This serves as the best estimate of the burden of drug resistant tuberculosis. As modelling is based on selected assumptions, its use is not meant to replace the ideal of robust routine data. The estimated drug resistant tuberculosis burden is shown in Table 2, and countries are ranked from highest to lowest. Nigeria (20 000) together with South Africa (19 000) account for $42 \%$ (39 000/92 629) of the total estimated burden, and thus their achievements or failures regarding drug resistant tuberculosis control will have a great impact on the overall picture for Africa. When the next three highest burden countries - Democratic Republic of Congo (7600), Mozambique (7600) and Ethiopia (5800) - are added, the cumulative figure accounts for $65 \%$ (60 000/92 629) of the estimated burden of cases. This highlights the obvious heterogeneity of disease burden among African countries and the need for a targeted response rather than a generalised one.

An interesting modelling study was undertaken by Musa et al. ${ }^{13}$ using available data sources, including surveys and published studies in sub-Saharan Africa, to estimate the trends and regional prevalence of drug resistant tuberculosis. The region with the highest prevalence was in the south of Africa with $3.1 \%(2.1 \%-4.2 \%)$ of tuberculosis cases being drug resistant. This was followed by central $(2.1 \% ; 1.1 \%-3.0 \%)$, western $(1.9 \% ; 1.2 \%-2.6 \%)$ and eastern $(1.7 \% ; 1.1 \%-2.2 \%)$ regions of sub-Saharan Africa. These prevalence estimates correlate well with recent surveys in the region.

Another modelling study by Sharma et al., ${ }^{14}$ which included four geographically diverse countries, predicted that there will be an increase in multi-drug resistant (MDR) tuberculosis across all four countries analysed and a decline in the relative contribution of acquired drug resistance. The MDR tuberculosis prevalence for South Africa come 2040 is predicted to be $5.7 \%$ (95\% prediction interval 3.0-7.6) compared with $12.4 \%$ (9.4-16.2) for India, 8.9\% (4.5-11.7) for the Philippines and 32.5\% (27.0-35.8) for Russia. Although the estimated prevalence is higher in other parts of the world, this needs to be seen in the context of the high incidence of tuberculosis in sub-Saharan Africa, thus, single digit changes in prevalence constitute substantial changes in absolute numbers. Furthermore, the prediction of a global increase has implications for Africa, and the authors indicated that existing activities through the Green Light Committee will not be sufficient to change this trend.

The most recent survey in South Africa (2012-2014), compared to the previous one conducted just over 10 years earlier, showed an almost doubling of the rate in rifampicin resistance $(1.8 \% \text { to } 3.4 \%)^{15}$ Also a similar increasing rate of resistance was observed in Botswana from 2.0\% to 3.6\% between 2002 and 2007-2008. ${ }^{16}$ The increase observed was primarily in new cases for both countries and driven by rifampicin mono-resistant tuberculosis, particularly in the South African survey. The increase in rifampicin resistant (RR) tuberculosis among new cases highlights the role of primary drug resistant tuberculosis transmission, which is likely to occur due to missed diagnostic opportunities when patients are not tested and treated for drug-resistant tuberculosis, or never reach health services. This has been the major obstacle in the era preceding the introduction of molecular diagnostics $\left(\right.$ Xpert $^{\circledR}$ MTB/RIF [Cepheid, Sunnyvale, California, United States] and line probe assays), which still continues to persist. Of importance as well is the higher rate of isoniazid mono-resistance (6.1\%) compared to any rifampicin resistance (4.6\%) in the 2012-2014 South Africa survey, with the former also associated with poorer treatment outcomes.

Comparing the estimated burden of drug resistant tuberculosis to cases notified, there is an alarming notification gap, as only 27828 of the 92629 estimated cases were notified. This suggests that $70 \%$ of cases in Africa are being missed. In addition, the proportion of missed RR and MDR tuberculosis cases are estimated to be above $50 \%$ for 43 of the 47 African countries (Table 1). It should be noted that the confidence intervals are relatively wide, yet using the lower estimate the gap is $45 \%$. The extremely drug resistant tuberculosis estimates are not available for comparison; however, a total of 1092 extremely drug resistant tuberculosis cases were notified, of which South Africa reported 89\% (967) of all extremely drug resistant tuberculosis cases on the continent. ${ }^{17}$ This disproportionality is most likely due to lack of capacity to diagnose extremely drug resistant tuberculosis in Africa. Only 53\% of RR and MDR tuberculosis cases in Africa had second-line drug susceptibility testing performed, and $47 \%(22 / 47)$ of member states do not have a laboratory that can perform second-line resistance testing (Table 3). 
TABLE 1: Rifampicin resistance detection in Africa from policy to application.

\begin{tabular}{|c|c|c|c|c|c|c|c|}
\hline Country & Population & $\begin{array}{l}\text { Policy WRD as } \\
\text { initial test }\end{array}$ & $\begin{array}{l}\text { No. of Xpert MTB/ } \\
\text { RIF sites }\end{array}$ & $\begin{array}{l}\text { Xpert MTB/RIF } \\
\text { population } \\
\text { (per million) }\end{array}$ & $\begin{array}{c}\text { New incident } \\
\text { tuberculosis cases }\end{array}$ & Rifampicin DST & $\begin{array}{c}\text { Proportion of } \\
\text { tuberculosis cases } \\
\text { with rifampicin DST } \\
(\%)\end{array}$ \\
\hline Mauritius & 1262132 & - & - & 0.0 & 121 & 114 & 94 \\
\hline South Africa & 56015473 & Yes & 207 & 3.7 & 237045 & 215696 & 91 \\
\hline Swaziland & 1343098 & Yes & 28 & 20.8 & 3567 & 2915 & 82 \\
\hline Senegal & 15411614 & No & 12 & 0.8 & 12878 & 8934 & 69 \\
\hline Rwanda & 11917508 & Yes & 47 & 3.9 & 5792 & 3849 & 66 \\
\hline Gambia & 2038501 & Yes & 1 & 0.5 & 2498 & 1644 & 66 \\
\hline Seychelles & 94228 & - & - & 0.0 & 12 & 6 & 50 \\
\hline Mozambique & 28829476 & Yes & 63 & 2.2 & 71842 & 35880 & 50 \\
\hline Ethiopia & 102403196 & No & 138 & 1.3 & 125836 & 56509 & 45 \\
\hline Nigeria & 185989640 & Yes & 318 & 1.7 & 97279 & 39819 & 41 \\
\hline Ghana & 28206728 & No & 105 & 3.7 & 14167 & 5359 & 38 \\
\hline Uganda & 41487965 & Yes & 111 & 2.7 & 43413 & 12065 & 28 \\
\hline Kenya & 48461567 & Yes & 130 & 2.7 & 76335 & 20884 & 27 \\
\hline Liberia & 4613823 & Yes & 9 & 2.0 & 7105 & 1876 & 26 \\
\hline $\begin{array}{l}\text { Sao Tome and } \\
\text { Principe }\end{array}$ & 199910 & Yes & 1 & 5.0 & 188 & 40 & 21 \\
\hline Cabo Verde & 23439189 & No & 2 & 0.1 & 247 & 50 & 20 \\
\hline Zimbabwe & 16150362 & Yes & 116 & 7.2 & 27353 & 5282 & 19 \\
\hline Guinea & 12395924 & No & 10 & 0.8 & 12639 & 2421 & 19 \\
\hline Malawi & 18091575 & No & 42 & 2.3 & 15516 & 2897 & 19 \\
\hline $\begin{array}{l}\text { United Republic of } \\
\text { Tanzania }\end{array}$ & 55572201 & Yes & 68 & 1.2 & 64609 & 9949 & 15 \\
\hline Mali & 17994837 & Yes & 8 & 0.4 & 6776 & 1036 & 15 \\
\hline Gabon & 1979786 & No & 2 & 1.0 & 5567 & 639 & 11 \\
\hline Cote d'Ivoire & 539560 & No & 13 & 24.1 & 21357 & 2358 & 11 \\
\hline $\begin{array}{l}\text { Democratic Republic } \\
\text { of the Congo }\end{array}$ & 78736153 & No & 60 & 0.8 & 130596 & 13273 & 10 \\
\hline Togo & 7606374 & No & 1 & 0.1 & 2755 & 236 & 9 \\
\hline Burundi & 10524117 & Yes & 6 & 0.6 & 7567 & 615 & 8 \\
\hline Equatorial Guinea & 1221490 & No & 2 & 1.6 & 1428 & 105 & 7 \\
\hline Benin & 10872298 & No & 6 & 0.6 & 3891 & 280 & 7 \\
\hline Burkina Faso & 18646433 & No & 15 & 0.8 & 5677 & 376 & 7 \\
\hline Eritrea & 4954645 & No & 15 & 3.0 & 2215 & 144 & 7 \\
\hline Cameroon & 4594621 & No & 14 & 3.0 & 25975 & 1541 & 6 \\
\hline South Sudan & 12230730 & No & 2 & 0.2 & 10770 & 536 & 5 \\
\hline Madagascar & 24894551 & No & 5 & 0.2 & 29001 & 1428 & 5 \\
\hline Namibia & 2479713 & Yes & 25 & 10.1 & 8857 & 387 & 4 \\
\hline Congo & 23695919 & No & 1 & 0.0 & 10424 & 336 & 3 \\
\hline Chad & 795601 & No & 3 & 3.8 & 10777 & 339 & 3 \\
\hline Niger & 20672987 & No & 4 & 0.2 & 9921 & 287 & 3 \\
\hline Botswana & 2250260 & Yes & 34 & 15.1 & 4803 & 104 & 2 \\
\hline Central African Republic & 14452543 & Yes & 1 & 0.1 & 9968 & 206 & 2 \\
\hline Zambia & 16591390 & Yes & 69 & 4.2 & 38326 & 526 & 1 \\
\hline Angola & 28813463 & Yes & 15 & 0.5 & 59513 & 452 & 1 \\
\hline Comoros & 5125821 & - & - & 0.0 & 163 & 1 & 1 \\
\hline Sierra Leone & 7396190 & No & 6 & 0.8 & 14114 & 60 & 0 \\
\hline Algeria & 40606052 & Yes & 1 & 0.0 & 22801 & 89 & 0 \\
\hline Mauritania & 4301018 & No & 0 & 0.0 & 2359 & 8 & 0 \\
\hline Lesotho & 2203821 & Yes & 22 & 10.0 & 7291 & 0 & 0 \\
\hline Guinea-Bissau & 1815698 & No & 2 & 1.1 & 2226 & 0 & 0 \\
\hline Africa & 1019920181 & 21 & 1740 & 1.7 & 1273560 & 451551 & 35 \\
\hline
\end{tabular}

Source: WHO Global TB database. ${ }^{10}$

DST, drug susceptibility testing; WRD, WHO-endorsed rapid diagnostic.

Mortality reduction is another important target of WHO's 2035 End TB Strategy. Missed cases contribute to mortality directly when cases are not detected through current programmes, or indirectly due to late presentation or testing for resistance being unavailable. The overall MDR tuberculosis mortality for the 2014 Africa cohort $(N=16231)$ was $20 \%$, while treatment success was only $58 \%$ (Figure 1 ). The situation was far worse for the extremely drug resistant tuberculosis cohort in $2014(N=623)$ with mortality at $42 \%$ and treatment success at only $27 \%$. Outcomes for the 2014 cohort of MDR tuberculosis by country are shown in Figure 1.

Reviewing the diagnostic landscape for drug resistant tuberculosis in Africa, encouraging signs are noted with $45 \%$ 
TABLE 2: Comparison of rifampicin-resistant and multi-drug-resistant tuberculosis burden estimated with notified, ordered from highest to lowest estimated burden: 2016

\begin{tabular}{|c|c|c|c|c|c|c|c|c|}
\hline Country & $\begin{array}{l}\text { RR/MDR } \\
\text { estimated }\end{array}$ & $\begin{array}{c}\text { RR/MDR } \\
\text { estimated (low) }\end{array}$ & $\begin{array}{c}\text { RR/MDR } \\
\text { estimated (high) }\end{array}$ & RR/MDR notified & $\begin{array}{c}\text { Missing RR/MDR } \\
(\%)\end{array}$ & $\begin{array}{l}\text { Missing RR/MDR } \\
\text { (low) (\%) }\end{array}$ & $\begin{array}{c}\text { Missing RR/MDR } \\
\text { (high) (\%) }\end{array}$ & Most recent DRS \\
\hline Nigeria & 20000 & 12000 & 29000 & 1686 & 92 & 86 & 94 & 2010 \\
\hline South Africa & 19000 & 12000 & 25000 & 19073 & 0 & -59 & 24 & 2014 \\
\hline $\begin{array}{l}\text { Democratic Republic of } \\
\text { the Congo }\end{array}$ & 7600 & 3900 & 11000 & 709 & 91 & 82 & 94 & 2017 \\
\hline Mozambique & 7600 & 4500 & 11000 & 911 & 88 & 80 & 92 & 2007 \\
\hline Ethiopia & 5800 & 3100 & 8500 & 700 & 88 & 77 & 92 & 2005 \\
\hline Kenya & 3000 & 1600 & 4400 & 326 & 89 & 80 & 93 & 2014 \\
\hline $\begin{array}{l}\text { United Republic of } \\
\text { Tanzania }\end{array}$ & 2600 & 630 & 4600 & 196 & 92 & 69 & 96 & 2007 \\
\hline Cote d'Ivoire & 2100 & 1100 & 3100 & 440 & 79 & 60 & 86 & 2017 \\
\hline Zambia & 2100 & 1400 & 2900 & 180 & 91 & 87 & 94 & 2008 \\
\hline Uganda & 1900 & 980 & 2900 & 489 & 74 & 50 & 83 & 2011 \\
\hline Zimbabwe & 1900 & 1300 & 2600 & 572 & 70 & 56 & 78 & 2016 \\
\hline Lesotho & 1100 & 710 & 1400 & - & 100 & 100 & 100 & 2014 \\
\hline Namibia & 960 & 740 & 1200 & 360 & 63 & 51 & 70 & 2015 \\
\hline Ghana & 840 & 270 & 1400 & 107 & 87 & 60 & 92 & 2017 \\
\hline Chad & 760 & 160 & 1400 & 45 & 94 & 72 & 97 & - \\
\hline Guinea & 730 & 140 & 1300 & 178 & 76 & -27 & 86 & - \\
\hline Sierra Leone & 720 & 120 & 1300 & 13 & 98 & 89 & 99 & - \\
\hline Niger & 660 & 140 & 1200 & 49 & 93 & 65 & 96 & - \\
\hline South Sudan & 660 & 430 & 900 & 13 & 98 & 97 & 99 & - \\
\hline Swaziland & 660 & 340 & 980 & 181 & 73 & 47 & 82 & 2009 \\
\hline Congo & 640 & 390 & 900 & 29 & 95 & 93 & 97 & - \\
\hline Algeria & 460 & 140 & 780 & 31 & 93 & 78 & 96 & 2002 \\
\hline Madagascar & 440 & 81 & 790 & 40 & 91 & 51 & 95 & 2007 \\
\hline Senegal & 440 & 280 & 610 & 64 & 85 & 77 & 90 & 2014 \\
\hline Liberia & 430 & 46 & 820 & 92 & 79 & -100 & 89 & - \\
\hline Gabon & 400 & 290 & 500 & 30 & 93 & 90 & 94 & - \\
\hline Malawi & 400 & 130 & 670 & 66 & 84 & 49 & 90 & 2011 \\
\hline Mali & 380 & 100 & 660 & 386 & -2 & -286 & 42 & - \\
\hline Burkina Faso & 300 & 180 & 410 & 58 & 81 & 68 & 86 & 2017 \\
\hline Guinea-Bissau & 200 & 17 & 390 & 37 & 82 & -118 & 91 & - \\
\hline $\begin{array}{l}\text { Central African } \\
\text { Republic }\end{array}$ & 180 & 0 & 410 & 57 & 68 & - & 86 & 2009 \\
\hline Eritrea & 140 & 28 & 260 & 24 & 83 & 14 & 91 & - \\
\hline Mauritania & 140 & 23 & 260 & 8 & 94 & 65 & 97 & - \\
\hline Rwanda & 140 & 89 & 190 & 81 & 42 & 9 & 57 & 2015 \\
\hline Equatorial Guinea & 110 & 55 & 170 & 32 & 71 & 42 & 81 & - \\
\hline Gambia & 110 & 18 & 200 & 2 & 98 & 89 & 99 & - \\
\hline Togo & 110 & 23 & 200 & 11 & 90 & 52 & 95 & - \\
\hline Benin & 97 & 2 & 190 & 18 & 81 & -800 & 91 & 2010 \\
\hline Comoros & 45 & 9 & 81 & 1 & 98 & 89 & 99 & - \\
\hline Cabo Verde & 29 & 9 & 48 & 0 & 100 & 100 & 100 & - \\
\hline Sao Tome and Principe & 10 & 5 & 15 & 3 & 70 & 40 & 80 & - \\
\hline Mauritius & 8 & 0 & 17 & 3 & 63 & - & 82 & - \\
\hline Seychelles & 0 & 0 & 0 & 0 & - & - & - & - \\
\hline Africa & 92629 & 50435 & 135271 & 27828 & 70 & 45 & 79 & - \\
\hline
\end{tabular}

Source: WHO Global TB database. ${ }^{10}$

DRS, drug resistance survey; MDR, multi-drug resistant; RR, rifampicin resistant.

$(21 / 47)$ of countries having progressive policies, which include the use of the Xpert MTB/RIF assay as the initial WHO-endorsed rapid diagnostic test (Table 1). Comparing policy to practice, clear gaps emerge. Across the continent only $35 \%$ of newly diagnosed tuberculosis cases had a rifampicin drug susceptibility test performed (Table 1), implying that primary drug resistant tuberculosis cases are largely being missed. Rifampicin drug susceptibility testing was available for less than $10 \%$ of new cases in 23 countries. In contrast, Mauritius (94\%), South Africa (91\%), Swaziland (82\%), Senegal (69\%) and Rwanda (66\%) were ranked as the top five countries with high coverage for rifampicin drug susceptibility testing among notified cases. On the continent, the Xpert MTB/RIF is available in $43 / 47$ (91\%) countries, comprising 1740 testing sites (Table 1). Adjusted for population size, there is large variability ranging from less 
TABLE 3: Second-line resistance detection in Africa from policy to application.

\begin{tabular}{|c|c|c|c|c|c|c|c|}
\hline Country & $\begin{array}{c}\text { Policy on } \\
\text { universal DST }\end{array}$ & No. of LPAsI sites & $\begin{array}{l}\text { No. of DST-SLT } \\
\text { sites }\end{array}$ & $\begin{array}{l}\text { Confirmed RR/ } \\
\text { MDR tuberculosis }\end{array}$ & $\begin{array}{l}\text { No. of RR/MDR- } \\
\text { tuberculosis with } \\
\text { SLT }\end{array}$ & $\begin{array}{l}\text { Proportion of RR/ } \\
\text { MDR- tuberculosis } \\
\text { with SLT (\%) }\end{array}$ & $\begin{array}{l}\text { NRL ISO15189 } \\
\text { accredited }\end{array}$ \\
\hline Benin & No & 1 & 1 & 18 & 18 & 100 & Yes \\
\hline Cameroon & No & 1 & 1 & 176 & 176 & 100 & Yes \\
\hline Gabon & No & 1 & 1 & 30 & 30 & 100 & Yes \\
\hline Gambia & No & 0 & 0 & 2 & 2 & 100 & Yes \\
\hline Swaziland & No & 0 & 1 & 181 & 181 & 100 & Yes \\
\hline Equatorial Guinea & Yes & - & - & 32 & 32 & 100 & - \\
\hline Madagascar & Yes & 0 & 1 & 40 & 40 & 100 & No \\
\hline Mauritius & Yes & - & - & 3 & 3 & 100 & - \\
\hline Sierra Leone & Yes & 0 & 0 & 13 & 13 & 100 & No \\
\hline Mozambique & Yes & 0 & 1 & 911 & 868 & 95 & Yes \\
\hline Niger & Yes & 1 & 1 & 49 & 34 & 69 & No \\
\hline Cote d'Ivoire & No & 0 & 0 & 440 & 300 & 68 & No \\
\hline Burundi & No & 0 & 1 & 80 & 52 & 65 & Yes \\
\hline Kenya & Yes & 1 & 5 & 326 & 204 & 63 & Yes \\
\hline South Africa & Yes & 7 & 7 & 19073 & 11903 & 62 & Yes \\
\hline Zimbabwe & No & 2 & 1 & 572 & 301 & 53 & Yes \\
\hline United Republic of Tanzania & No & - & 1 & 196 & 97 & 49 & Yes \\
\hline Rwanda & No & 1 & 1 & 81 & 35 & 43 & No \\
\hline Algeria & - & 1 & 1 & 31 & 13 & 42 & Yes \\
\hline Senegal & Yes & 1 & 1 & 64 & 22 & 34 & No \\
\hline Democratic Republic of the Congo & No & 1 & 2 & 709 & 223 & 31 & No \\
\hline Uganda & Yes & 0 & 4 & 489 & 101 & 21 & Yes \\
\hline Namibia & No & 1 & 1 & 360 & 54 & 15 & Yes \\
\hline Guinea & Yes & 1 & 1 & 178 & 26 & 15 & No \\
\hline Ethiopia & Yes & 1 & 1 & 700 & 28 & 4 & Yes \\
\hline Mali & No & 0 & 2 & 386 & 6 & 2 & Yes \\
\hline Chad & No & - & - & 45 & 0 & 0 & - \\
\hline Congo & No & 1 & 1 & 29 & - & 0 & Yes \\
\hline Eritrea & No & 0 & 0 & 24 & 0 & 0 & Yes \\
\hline Ghana & No & 0 & 0 & 107 & 0 & 0 & Yes \\
\hline Guinea-Bissau & No & 0 & 0 & 37 & - & 0 & No \\
\hline Malawi & No & - & - & 66 & 0 & 0 & Yes \\
\hline Sao Tome and Principe & No & 0 & 0 & 3 & 0 & 0 & No \\
\hline South Sudan & No & 0 & 0 & 13 & - & 0 & No \\
\hline Angola & Yes & 0 & 3 & 167 & 0 & 0 & No \\
\hline Botswana & Yes & 1 & 1 & 104 & 0 & 0 & Yes \\
\hline Burkina Faso & Yes & 1 & 0 & 58 & 0 & 0 & No \\
\hline Central African Republic & Yes & 0 & 0 & 57 & 0 & 0 & No \\
\hline Nigeria & Yes & 2 & 2 & 1686 & - & 0 & Yes \\
\hline Zambia & Yes & 1 & 3 & 180 & 0 & 0 & Yes \\
\hline Comoros & - & 0 & 0 & 1 & 0 & 0 & No \\
\hline Liberia & - & 0 & 0 & 92 & 0 & 0 & Yes \\
\hline Mauritania & - & 0 & 0 & 8 & 0 & 0 & No \\
\hline Togo & - & 0 & 0 & 11 & 0 & 0 & No \\
\hline Cabo Verde & No & 2 & 2 & 0 & 0 & - & Yes \\
\hline Seychelles & No & - & - & 0 & 0 & - & - \\
\hline Lesotho & Yes & 0 & 0 & - & - & - & Yes \\
\hline Africa & 19 & 29 & 48 & 27828 & 14762 & 53 & 26 \\
\hline
\end{tabular}

Source: WHO Global TB database. ${ }^{10}$

DST, drug susceptibility testing; NRL, National Reference Laboratory ; SLT, second-line testing.

than 1 to 24 sites per million people. Albeit a crude measurement, it does highlight important gaps in coverage for many countries. However, coverage of drug susceptibility testing does not directly imply utilisation, which is likely to be even poorer.

Policies on universal drug susceptibility testing are also lacking with $19(40 \%)$ of the 47 countries having a policy in place (Table 3). The GenoType MTBDRsl (Hain Life Sciences, Nehren, Germany) for second-line drug susceptibility testing is available in 20 of $47(43 \%)$ countries at 29 sites (Table 3). This proportion is unsurprisingly low as the GenoType MTBDRsl has only been recently endorsed to address gaps in second-line drug susceptibility testing. Overall, 28 (60\%) countries have second-line drug susceptibility testing available, using either line probe assay or phenotypic drug susceptibility testing 


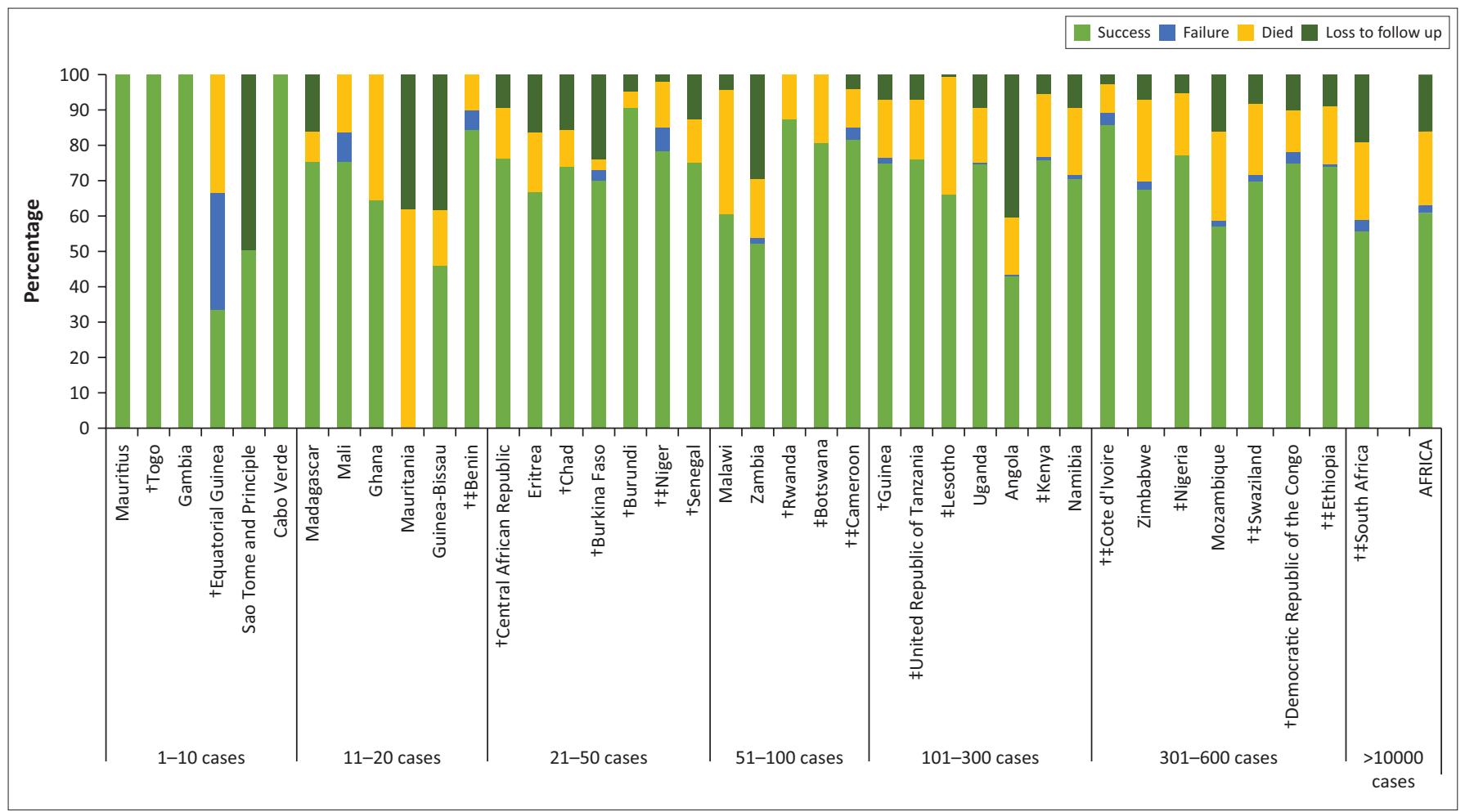

Source: WHO Global TB database. ${ }^{10}$

MDR, multi-drug resistant.

$\dagger$, implemented short MDR tuberculosis regimen (not shown: Comoros and Gabon).

$\$$, implemented bedaquiline for MDR tuberculosis management.

FIGURE 1: Multi-drug-resistant tuberculosis outcomes by country grouped by size of cohort: 2014. Countries with no data or no reported cases are not shown.

(Table 3). Availability of second-line drug susceptibility testing has, however, not translated into practice with only $43 \%$ $(12 / 28)$ of these countries testing more than half their notified rifampicin-resistant tuberculosis cases. However, these percentages are not truly reflective, as they are based on the number of detected rather than estimated cases.

Another important issue with respect to laboratories is quality assurance. Among all African countries, 26 (55\%) national reference laboratories (NRLs) reported having an ISO 15189 accreditation status. Although this does seem encouraging, this reporting may not be a true reflection of the situation, as the reference laboratories that are formally recognised by SLMTA ${ }^{18}$ as being accredited based on external evaluation are the NRLs of Ethiopia, Mozambique, South Africa and Uganda. ISO 15189 accreditation should be a basic requirement for this level of laboratory. In the absence of accreditation, participation in external quality assurance programmes provides a basic measure of quality evaluation and competence while countries progress towards accreditation and has been introduced for high burden countries through the WHO.

Apart from diagnostics, treatment is an essential component of tuberculosis control as well and affects a country's ability to reach the WHO End TB Strategy targets. Drug resistant tuberculosis treatment is often prolonged and uses less effective regimens with more adverse events compared to first-line treatment. The number of cases reported on treatment per country varies (Figure 1), with all but one treating less than 600 cases in a year (South Africa: > 10000 ). The treatment success overall in Africa was 59\%, 20\% died and 16\% were lost to followup (Appendix 1). The introduction of the short-course regimen is a major improvement and, in 2016, 36\% (17/47) of countries used this patient friendly regimen (Figure 1). Countries leading the implementation of this regimen were Democratic Republic of Congo (555), Cote d'Ivoire (349) and Cameroon (135) with 31\%, 68\% and 100\% of RR and MDR tuberculosis patients in these countries, respectively also having second-line drug susceptibility testing performed. Thus, adoption of the short-course regimen is not strictly linked to second-line drug susceptibility testing; however, in light of the recent rapid WHO guidance, the need for early identification of fluoroquinolone resistance is important. The top three countries with at least 50 cases or more and having the highest treatment success were countries implementing the short-course regimen: Burundi (90\%), Rwanda (88\%) and Cote d'Ivoire (85\%). Bedaquiline is a new and welcome addition to drug resistant tuberculosis management and is reported to be highly effective. ${ }^{19,20}$ It is currently being used in 11 African countries as well as in South Africa where its use is on a large scale (Figure 1). This new agent also offers a potential for scale-up in addressing poor treatment outcomes for drug resistant tuberculosis. 


\section{Towards ending drug resistant tuberculosis in Africa}

Drug resistant tuberculosis poses a major hurdle to achieving the WHO End TB Strategy targets. Acting early and decisively will be a determining factor in either future success or failure. Encouragingly, the past 5 years have seen new diagnostic technologies and treatment options become available, as well as strong global political commitment to end tuberculosis. Despite the obstacles threatening the realisation of the WHO End TB Strategy targets in Africa, there are equally effective tools available for achieving success.

Primary among the urgent needs is a clear understanding of the burden of tuberculosis and drug resistant tuberculosis, which will greatly impact planning and efficient resource allocation, a key issue in resource-constrained environments. Progress has been made with just over half of the countries ever having completed a survey. However, there are still large gaps in the data available and these need to be urgently addressed. Furthermore, in order to assess progress and respond appropriately, trend data is essential. The use of routine data reported to the WHO has added benefits, but concerns about accuracy and completeness result in this information being treated with circumspection. Modelled estimates using this routine data would also be impacted as a consequence.

An alternative approach to address gaps is the use of sentinel surveillance for tracking annual trends in strategically selected sites. This is a potential hybrid solution, which is being considered by the HIV programme. ${ }^{21}$ Such a system has been used in South Africa for tuberculosis, and unpublished data do support the value of such an approach. This approach can be achieved with far fewer resources and has the potential to strengthen existing routine systems and serve as a starting point for replication of developed sites in other areas. Ensuring routine standardised algorithms detecting rifampicin and second-line resistance is the ideal and should be facilitated in the era of the Xpert MTB/RIF and GenoType MTBDRsl. A few countries have shown high uptake of rapid diagnostic tools for early rifampicin and second-line resistance detection. These efforts should be standardised to ensure data comparisons between countries and regions of Africa.

Another key concern is missing cases, which are estimated to be equal to or greater than the notified burden. Although the numbers are staggering, modifying current diagnostic algorithms to adopt new technologies could dramatically reduce this gap in a short period of time and can be seen in some countries already. The utilisation of the Xpert MTB/RIF has been lacklustre on the continent, with many countries limiting its use to selected cases and thus diminishing the impact of this critical molecular diagnostic platform. This not only reduces the detection of tuberculosis by approximately $10 \%-20 \%{ }^{22}$ but also means that by design, rifampicin resistance is missed almost completely in the vast majority of tuberculosis cases. It should be noted that although the prevalence of drug resistant tuberculosis is higher in previously treated cases compared to new cases, the absolute number of drug resistant tuberculosis patients among previously treated cases is far lower than the numbers in new tuberculosis cases. For the 2015 cohort, 1200078 new and relapsed drug resistant tuberculosis cases were notified, of which only 38059 were previously treated cases. ${ }^{3}$ The net effect is a similar burden in absolute numbers of drug resistant tuberculosis between new and previously treated cases. This is because previously treated cases, despite having a much higher prevalence of drug resistant tuberculosis cases, contribute only to a small part of the total TB burden.

Aggressive scale-up of the use of rapid molecular diagnostic tools (e.g. Xpert) as the primary test will be key to finding missing drug resistant tuberculosis cases and is all the more urgent as primary transmission is a major contributor to the propagation of the disease. ${ }^{15,22}$ Missing resistance may result in poorer outcomes, and further compromises the health and well-being of the population at large. In addition, stigma and lack of access to health services are known obstacles to care and likely contribute to missing cases. Some of these cases will most likely end up at a health facility and the unavailability of quality diagnostic technologies would lead to a catastrophic treatment failure. Several countries other than South Africa have taken the approach of using the Xpert MTB/RIF as the primary test for the detection of tuberculosis and drug resistant tuberculosis, and thus models for implementation are available. The South African approach uses a central model with important emphasis on logistics, which has worked well. In regions where transport infrastructure is limited, the use of the GeneXpert Omni (Cepheid, Sunnyvale, California, United States) could be an effective solution. The greater focus now is on multiplex diagnostic platforms that will also facilitate integration at different levels of the health system, thereby providing improved diagnostic yield. Irrespective of the approach, careful planning and budgeting will be needed in order to achieve the necessary returns.

A second issue relates to second-line testing. While this is being achieved in several African countries with good overall coverage among notified RR tuberculosis cases (Table 3), it is often a challenge in most settings across Africa with $43 \%$ $(20 / 47)$ of member states having no coverage. As the overall reported burden of drug resistant tuberculosis is not particularly high in many countries, the need and operational feasibility to set up such systems may be better served through regional collaboration. There are three WHOcertified supranational reference laboratories in Africa ${ }^{24}$ and several NRLs that have adequate capacity to provide such services. While this would lead to increase in volumes of second-line testing, it will also ensure operational efficiency and allow skills to be developed and sustained. Linked to such services is also the need for supporting surveys on the continent. 
The three supranational reference laboratories are limited by capacity to provide for the large needs of the continent. Expanding the number of supranational reference laboratories is required and NRLs with potential should be supported to achieve this status. The number of NRLs complying with ISO 15189 is still unacceptably low, considering that NRLs are expected to be the standard against which sub-national laboratories are compared. The introduction of the Strengthening Laboratory Management Toward Accreditation programme has seen 54 laboratories achieve accreditation by the end of 2017 over a 5 -year period, ${ }^{25}$ however, only two were national tuberculosis reference laboratories. Prioritisation of NRLs to achieve accreditation should be a short-term goal using Strengthening Laboratory Management Toward Accreditation. The emergence of the new Africa Centres for Disease Control and Prevention portends hope through the introduction and implementation of the regional integrated laboratory and surveillance network hosted through the five Regional Collaborating Centres in the five geographical sub-regions of the African Union. It is anticipated that these centres, and the associated network, can be used to improve and strengthen diagnostic capabilities within the Africa region.

The continuum of care requires not only good diagnostics but also effective early treatment. Successful outcomes among MDR tuberculosis patients are exceptionally low with death and loss to follow-up being common endpoints. These are complex issues underpinned by late presentation, poor access to services and overburdened health services. Treatment options are another important determinant of patient outcomes. Therapy is often prolonged; however, a short-course regimen has shown promise in reducing the loss of patients to follow-up. The highest success rates observed in Africa were among those applying this approach and, importantly, a large evidence base for this policy came from Africa and confirms its value. ${ }^{25}$ The introduction of the short regimen requires greater impetus to ensure it is accessible and widely used, as currently only $36 \%$ of countries have introduced it.

More positive news out of Africa is the use of bedaquiline, with significant reductions observed in mortality for both MDR and XDR tuberculosis cases using this agent. ${ }^{26}$ This too is a timely improvement in addressing urgent issues in the management of drug resistant tuberculosis. South Africa has scaled up its use, but it has only recently been introduced in 11 countries. Time lost due to slow scale-up will result in preventable deaths and further transmission. Additionally, skills in dealing with complex drug interactions and adverse events are available, particularly in South Africa, and South-South collaboration can facilitate the safe and effective introduction of the new agents. The availability of a second agent - delamanid - is another promising advancement and opens the way for potentially effective combination therapy to be standardised for XDR tuberculosis treatment. This would simplify management of these complex cases, especially for areas where skills may be lacking. The Global Drug Facility is an important mechanism for access to new drugs for the treatment of drug resistant tuberculosis in Africa and can be utilised to improve the management of drug resistant tuberculosis.

As highlighted, South-South collaborations are important, and findings reported by Cain et al. ${ }^{27}$ demonstrate the impact of migration and management of drug resistant tuberculosis. These authors showed that a large and increasing case load of MDR tuberculosis patients from specific areas of Somalia crossed borders to Kenya, seeking care due to lack of services. Migration is an important contributor to missing cases and may lead to poor outcomes. Similar migratory behaviour has been documented in other regions on the continent related to employment seeking in the mining sector. ${ }^{28}$ Dealing with migration and the continuum of care requires common standards of care to be available, good communication and referral mechanisms, as well as a unique identifier to link patients across countries and regions. Although this issue has received some attention from the regions, the impetus has been slow and coordination weak. The launch of the Africa Centres for Disease Control as well as Prevention and its Regional Collaborating Centres and target national public health institutes does offer a potential coordination mechanism and should be prioritised. The Innovation in Laboratory Engineered Accelerated Diagnostics project is a new initiative and will use biometrics ${ }^{29}$ as the unique patient identifier across regions. If successful, it will provide a model to allow patients to be managed through care irrespective of where they are diagnosed.

Ending tuberculosis and specifically drug resistant tuberculosis cannot be fully realised without dealing with HIV infection and disease. HIV/AIDS is a major contributor to the burden of both tuberculosis and drug resistant tuberculosis, and current efforts at also ending HIV are encouraging. Achieving viral suppression at a population level is an important tuberculosis prevention strategy and will likely lead to continued declines in HIVassociated tuberculosis and drug resistant tuberculosis. This would, however, result in a relatively higher proportion of HIV-negative tuberculosis and drug resistant tuberculosis. This group is less likely to die and, consequently, can transmit for longer periods. Thus, missing such cases will have long-term consequences, and messages to ensure this group is also investigated will be increasingly important. Another issue that should be appreciated is that the burden of tuberculosis and drug resistant tuberculosis has for many years exceeded the existing medical care capacity, leading to failures in health delivery. In spite of this, the declines seen offer a window of hope where the developed capacity and burden may align once again. Thus, the need to maintain funding and capacity during this period is needed if we are to end tuberculosis by 2035 . 


\section{Limitations}

It is important to contextualise the limitations of this analysis. The data used were taken from the WHO global tuberculosis database, which derived data from countries through unverified self-reporting. Countries are usually given time to verify their data before submission and, in addition, anomalies identified by WHO result in queries sent back to countries for checking before the data are accepted. Additionally, the estimates included are based on established mathematical models adopted for use by WHO and are inherently influenced by the assumptions applied to the model. The wide confidence intervals account for the uncertainty in deriving these estimates.

\section{Conclusion}

Drug resistant tuberculosis is difficult to manage even in the best of environments and is likely to pose a major challenge for Africa as it works toward achieving the WHO End TB Strategy targets. Any delays in addressing drug resistant tuberculosis will mean lost ground, which will make the challenge even greater. Our ability to end tuberculosis and, specifically, drug resistant tuberculosis, by 2035 will require a major uphill effort, but it is achievable given the right strategic focus complemented by strong leadership and adequate resources. The adage 'know your epidemic, and know your response' serves as a guiding principle leading up to 2035 and we have provided detailed data clearly highlighting areas of success and failure. It is clear that the burden is highly heterogeneous, and focusing on key countries will be greatly rewarding, if available resources are used wisely. Gaps in data are also large and certainty needs to be achieved on the true burden of tuberculosis and drug resistant tuberculosis throughout the continent. Experience gained in addressing the deficiencies identified here could influence prioritisation within the tuberculosis control programme in the future. The advent of new and improved diagnostics constitutes a major advancement, although adoption has not been aggressive enough in many parts of Africa, and this needs greater impetus. Despite shortcomings as a continent, African countries have played a leading role for both the evaluation of drug resistant tuberculosis diagnostic tools and treatment options, which include the short regimen and bedaquiline. These findings need to move to scale rapidly for us to accelerate progress in dealing with drug resistant tuberculosis and ultimately end the disease.

\section{Acknowledgements}

We would like to thank all the national tuberculosis control programmes that contributed important public health data to the WHO global tuberculosis database. We also thank the WHO headquarters and regional offices for ensuring the data collected were standardised and reviewed before making the information publicly available.

\section{Competing interests}

The authors declare that they have no financial or personal relationships that may have inappropriately influenced them in writing this article.

\section{Sources of support}

None.

\section{Authors' contributions}

N.I., F.I. and P.C.O. were involved in the conception and design. N.I. and L.B. did the data analysis. N.I., F.I., S.V.O., L.B., H.K., Y.G. and P.C.O. wrote the first draft. N.I., F.I., S.V.O., L.B., H.K., Y.G. and P.C.O. provided important intellectual input.

\section{References}

1. WHO. Global TB report. 2016 [cited 2018 January 22]. Available from: http:// www.who.int/tb/publications/global_report/gtbr2016_executive_summary.pdf

2. WHO. WHO END TB strategy. 2015 [cited 2018 January 22]. Available from: http:// www.who.int/tb/End_TB_brochure.pdf?ua=1

3. WHO. Global TB report. 2017 [cited 2018 August 27]. Available from: http://www. who.int/tb/publications/global_report/gtbr2016_executive_summary.pdf

4. Abdool Karim SS, Churchyard GJ, Karim QA, Lawn SD. HIV infection and tuberculosis in South Africa: An urgent need to escalate the public health
response. Lancet. 2009;374(9693):921-933. https://doi.org/10.1016/S0140response. Lancet.

5. Harries AD, Hargreaves NJ, Kemp J, et al. Deaths from tuberculosis in sub-Saharan African countries with a high prevalence of HIV-1. Lancet. 2001:357(9267):15191523. https://doi.org/10.1016/S0140-6736(00)04639-0

6. Takarinda $K C$, Harries AD, Sandy C, Mutasa-Apollo T, Zishiri C. Declining tuberculosis case notification rates with the scale-up of antiretroviral therapy in Zimbabwe. Public Health Action. 2016;6(3):164-168. https://doi.org/10.5588/pha.16.0029

7. Haumba $S$, Dlamini $T$, Calnan $M$, et al. Declining tuberculosis notification trend associated with strengthened TB and expanded HIV care in Swaziland. Public Health Action. 2015;5(2):103-105. https://doi.org/10.5588/pha.15.0008

8. Nanoo A, Izu A, Ismail NA, et al. Nationwide and regional incidence of microbiologically confirmed pulmonary tuberculosis in South Africa, 2004-2012 A time series analysis. Lancet Infect Dis. 2015;15(9):1066-1076. https://doi. org/10.1016/S1473-3099(15)00147-4

9. Mariandyshev A, Eliseev P. Drug-resistant tuberculosis threatens WHO'S End-TB strategy. Lancet Infect Dis. 17(7):674-675. https://doi.org/10.1016/S14733099(17)30246-3

10. WHO. WHO's Global TB Database. Geneva, Switzerland: WHO; 2016.

11. WHO. Guidelines for surveillance of drug resistant tuberculosis. 5 th ed. Geneva, Switzerland: WHO; 2015

12. WHO. Methods used by WHO to estimate the global burden of TB disease. 2016 [cited 2017 December 16]. Available from: http://www.who.int/tb/publications/ global_report/gtbr2016_online_technical_appendix_global_disease_burden_ estimation.pdf

13. Musa BM, Adamu AL, Galadanci NA, Zubayr B, Odoh CN, Aliyu MH. Trends in prevalence of multi drug resistant tuberculosis in sub-Saharan Africa: A systematic review and meta-analysis. PLoS One 2017;12(9):e0185105. https://doi. org/10.1371/journal.pone.0185105

14. Sharma A, Hill A, Kurbatova E, et al. Estimating the future burden of multidrug resistant and extensively drug-resistant tuberculosis in India, the Philippines, resistant and extensively drug-resistant tuberculosis in India, the Philippines, 2017;17(7):707-715. https://doi.org/10.1016/S1473-3099(17)30247-5

15. NICD. South African TB drug resistance survey. 2015 [cited 2017 December 01]. Available from: http://www.nicd.ac.za/assets/files/K-12750\%20NICD\%20National $\%$ 20Survey\%20Report_Dev_V11-LR.pd

16. Menzies HJ, Moalosi G, Anisimova V, et al. Increase in anti-tuberculosis drug resistance in Botswana: Results from the fourth National Drug Resistance Survey. Int J Tuberc Lung Dis. 2014;18(9):1026-1033. https://doi.org/10.5588/ ijtld.13.0749

17. WHO. Global TB Report. 2017 [cited 2018 August 25]. Available from: http://www. who.int/tb/publications/global_report/gtbr2016_executive_summary.pdf

18. SLMTA. SLMTA Laboratories that have achieved accreditation. 2017 [cited 2018 August 30]; Available from: https://slmta.org/accredited-labs/

19. Diacon AH, Pym A, Grobusch MP, et al. Multidrug-resistant tuberculosis and culture conversion with bedaquiline. N Engl J Med. 2014;371(8):723-732. https:// doi.org/10.1056/NEJMoa1313865

20. WHO. The use of bedaquiline in the treatment of multidrug-resistant tuberculosis. 2013. [cited 2016 October 04]. Available from: http://apps.who.int/iris/ bitstream/10665/84879/1/9789241505482_eng.pdf

21. Raizes E, Hader S, Birx D. The US President's emergency plan for AIDS relief (PEPFAR) and HIV drug resistance: Mitigating risk, monitoring impact. J Infect Dis. 2017;216(suppl_9):S805-S807.

22. Steingart KR, Schiller I, Horne DJ, Pai M, Boehme CC, Dendukuri N. Xpert ${ }^{\oplus}$ Mtb/Rif assay for pulmonary tuberculosis and rifampicin resistance in adults. Cochrane Database Syst Rev. 2014;(1):1-166

23. Shah NS, Auld SC, Brust JC, et al. Transmission of extensively drug-resistant tuberculosis in South Africa. N Engl J Med. 2017;376(3):243-253. https://doi. org/10.1056/NEJMoa1604544 
24. WHO. WHO announces new TB Supranational Reference Laboratory in the African Region. 2017 [cited 2018 January 22]. Available from: http://www.who.int/tb/ features_archive/TB_supranational_reference_laboratory_AFRO/en/

25. Trebucq A, Schwoebel V, Kashongwe Z, et al. Treatment outcome with a short multidrug-resistant tuberculosis regimen in nine African countries. Int J Tuberc Lung Dis. 2018;22(1):17-25. https://doi.org/10.5588/ijtld.17.0498

26. Schnippel K, Ndjeka N, Maartens G, et al. Effect of bedaquiline on mortality in South African patients with drug-resistant tuberculosis: A retrospective cohort study. Lance Respir Med. 2018;6:699-706. https://doi.org/10.1016/S2213-2600(18)30235-2
27. Cain KP, Marano N, Kamene $\mathrm{M}$, et al. The movement of multidrug-resistant tuberculosis across borders in East Africa needs a regional and global solution. PLoS Med. 2015;12(2):e1001791. https://doi.org/10.1371/journal.pmed .1001791

28. Rees D, Murray J, Nelson G, Sonnenberg P. Oscillating migration and the epidemics of silicosis, tuberculosis, and HIV infection in South African gold miners. Am J Ind Med. 2010;53(4):398-404. https://doi.org/10.1002/ajim.20716

29. iLEAD. Innovation: Laboratory engineered accelerated diagnostics. 2017. [cited 2018 January 22]. Available from: http://ilead.org.za/ 


\section{Appendix 1}

TABLE 1-A1: MDR-TB outcomes in Africa: 2014.

\begin{tabular}{|c|c|c|c|c|c|c|c|c|c|}
\hline $\begin{array}{l}\text { Number of } \\
\text { cases }\end{array}$ & Country & $\begin{array}{c}\text { RR/MDR- } \\
\text { tuberculosis } \\
\text { cohort } 2014\end{array}$ & $\begin{array}{l}\text { Treatment } \\
\text { success }\end{array}$ & Treatment failure & Died & Loss to follow-up & $\begin{array}{l}\text { \% Successful } \\
\text { outcome }\end{array}$ & $\%$ Died & $\begin{array}{l}\% \text { Lost to } \\
\text { follow-up }\end{array}$ \\
\hline \multirow[t]{6}{*}{$1-10$ cases } & Mauritius & 1 & 1 & 0 & 0 & 0 & 100 & 0 & 0 \\
\hline & Togo† & 1 & 1 & 0 & 0 & 0 & 100 & 0 & 0 \\
\hline & Gambia & 2 & 2 & 0 & 0 & 0 & 100 & 0 & 0 \\
\hline & $\begin{array}{l}\text { Equatorial } \\
\text { Guinea† }\end{array}$ & 3 & 1 & 1 & 1 & 0 & 33 & 33 & 0 \\
\hline & $\begin{array}{l}\text { Sao Tome and } \\
\text { Principe }\end{array}$ & 4 & 2 & 0 & 0 & 2 & 50 & 0 & 50 \\
\hline & Cabo Verde & 5 & 5 & 0 & 0 & 0 & 100 & 0 & 0 \\
\hline \multirow[t]{6}{*}{$11-20$ cases } & Madagascar & 12 & 9 & & 1 & 2 & 75 & 8 & 17 \\
\hline & Mali & 12 & 9 & 1 & 2 & 0 & 75 & 17 & 0 \\
\hline & Ghana & 14 & 9 & 0 & 5 & 0 & 64 & 36 & 0 \\
\hline & Mauritania & 14 & 0 & 0 & 8 & 5 & 0 & 57 & 36 \\
\hline & Guinea-Bissau & 15 & 6 & 0 & 2 & 5 & 40 & 13 & 33 \\
\hline & Benintt & 19 & 16 & 1 & 2 & 0 & 84 & 11 & 0 \\
\hline & Eritrea & 24 & 16 & 0 & 4 & 4 & 67 & 17 & 17 \\
\hline & Chad $\dagger$ & 25 & 14 & 0 & 2 & 3 & 56 & 8 & 12 \\
\hline & Burkina Faso† & 34 & 23 & 1 & 1 & 8 & 68 & 3 & 24 \\
\hline & Burundi† & 41 & 37 & 0 & 2 & 2 & 90 & 5 & 5 \\
\hline & Nigertt & 46 & 36 & 3 & 6 & 1 & 78 & 13 & 2 \\
\hline & Senegal $\dagger$ & 48 & 36 & 0 & 6 & 6 & 75 & 13 & 13 \\
\hline \multirow[t]{5}{*}{$51-100$ cases } & Malawi & 53 & 31 & 0 & 18 & 2 & 58 & 34 & 4 \\
\hline & Zambia & 68 & 35 & 1 & 11 & 20 & 51 & 16 & 29 \\
\hline & Rwanda $\dagger$ & 80 & 70 & & 10 & 0 & 88 & 13 & 0 \\
\hline & Botswana & 86 & 63 & 0 & 15 & 0 & 73 & 17 & 0 \\
\hline & Cameroon $\dagger t$ & 91 & 74 & 3 & 10 & 4 & 81 & 11 & 4 \\
\hline \multirow[t]{6}{*}{$101-300$ cases } & Guinea† & 123 & 92 & 2 & 20 & 9 & 75 & 16 & 7 \\
\hline & $\begin{array}{l}\text { United Republic } \\
\text { of Tanzaniał }\end{array}$ & 143 & 108 & 0 & 25 & 10 & 76 & 17 & 7 \\
\hline & Uganda & 214 & 153 & 1 & 31 & 20 & 71 & 14 & 9 \\
\hline & Angola & 249 & 107 & 2 & 39 & 101 & 43 & 16 & 41 \\
\hline & Kenya: & 251 & 180 & 1 & 43 & 13 & 72 & 17 & 5 \\
\hline & Namibia & 266 & 186 & 4 & 49 & 26 & 70 & 18 & 10 \\
\hline \multirow[t]{7}{*}{$301-600$ cases } & Cote d'Ivoire $\dagger t$ & 311 & 265 & 13 & 23 & 10 & 85 & 7 & 3 \\
\hline & Zimbabwe & 381 & 193 & 6 & 66 & 21 & 51 & 17 & 6 \\
\hline & Nigeriał & 423 & 314 & 1 & 72 & 21 & 74 & 17 & 5 \\
\hline & Mozambique & 439 & 218 & 8 & 95 & 63 & 50 & 22 & 14 \\
\hline & Swaziland $\uparrow t$ & 444 & 310 & 8 & 88 & 38 & 70 & 20 & 9 \\
\hline & $\begin{array}{l}\text { Democratic } \\
\text { Republic of the } \\
\text { Congot }\end{array}$ & 448 & 334 & 16 & 51 & 46 & 75 & 11 & 10 \\
\hline & Ethiopia $\dagger+$ & 557 & 388 & 3 & 85 & 49 & 70 & 15 & 9 \\
\hline \multirow[t]{2}{*}{$>10000$ cases } & South Africa $\dagger t$ & 11111 & 6042 & 336 & 2410 & 2105 & 54 & 22 & 19 \\
\hline & Africa & 16231 & 9500 & 412 & 3254 & 2600 & 59 & 20 & 16 \\
\hline
\end{tabular}

Source: WHO Global TB database. ${ }^{10}$

Countries with no data or no reported cases are not shown.

$\dagger$, implemented short MDR tuberculosis regimen (not shown: Comoros and Gabon).

$\$$, implemented bedaquiline for MDR tuberculosis management.

$M D R$, multi-drug resistant; $R R$, rifampicin resistant. 